\title{
Investigating Collaborative Information Seeking Practice of Design Engineering Students
}

\author{
Nasser Saleh \\ Integrated Learning Librarian \\ Queen's University \\ nasser.saleh@queensu.ca
}

\begin{abstract}
Design engineering projects are reliant on collaborative effort among multiple individuals and/or departments through sharing experiments and data and collaboration on analysis of data and results. Information literacy is one of the competencies that design engineering students are expected to acquire through these courses, given that fact that students with an undergraduate Engineering degree will be at the entry level as professional engineers, the skills and tools they learn through their education will be their success keys in their profession, but the question is what information practice skills and tools that the industry expects that our students have acquired during design engineering courses and what are the information practice skills that students need to learn to meet employers' expectations?. This paper provides an overview of collaborative information practice and what role that librarians can do through the lifecycle of a design engineering course.
\end{abstract}

\section{Introduction}

More than twenty years ago, the National Science Board [1] issued a report on undergraduate science, mathematics, and engineering education. The report highlighted that undergraduate engineering education failed to prepare students to make the transition from school to work. As the bachelor of engineering is a terminal degree for engineers entering the work force, there are a lot of employers 'expectations about recent graduates' skills. In the following years there have been a lot of attention on undergraduate engineering programs; other reports had focused on the skills that students have to acquire during their studies including learning how to learn, lifelong leaning skills, and working in teams [2][3] . Also the National Academy of Engineering [4] has published a report on "What will or should engineering be like in 2020?” addressing the rapid changes in technology including the changes in the information field, and how those changes affect engineering education as engineering students are required to learn how to adopt different tools to remain knowledgeable and ready for "new scientific revolution".

The Canadian Engineering Accreditation Board (CEAB) establishes a number of criteria which a university engineering program must meet before receiving a formal accreditation. Programs are reassessed on a regular basis to ensure standards are maintained. One major emphasis is developing in students an understanding of the research process, including the ability to locate relevant information, and how to use it ethically and legally Clause 2.1.1 of CEAB's accreditation manual is "The criteria [of accreditation] are intended to identify those programs that develop an individual's ability to use appropriate knowledge and information to convert, utilize and manage resources optimally through effective analysis, interpretation and decision-making. This ability is essential to the design process that characterizes the practice of engineering." [5]. Information practice is changing so quickly that graduates will not succeed without the necessary skills to enable them to acquire needed information readily and easily. Students' recognition of the needs for information, and the ability engage to lifelong learning is also one of the criteria addressed by the Accreditation Board for Engineering and Technology [6] is that lifelong learning would be impossible without an understanding of the infrastructure underlying our information rich environment.

In Practice, engineering librarians often adopt the framework of Information Literacy Standards for Science and Engineering/ Technology that is developed by the Association of College and Research Libraries (ACRL), with the definition of information literacy as "a set of abilities requiring individuals to recognize when information is needed 
and then have the ability to locate, evaluate, and use effectively the needed information”. ACRL information literacy competency standards defines five standards and twenty-five performance indicators that are accompanied by one or more outcomes for assessing the student's progress toward information literacy, given the fact that the majority of universities and colleges do not have a separate course for information literacy per se for undergraduate students, so the assessment of students information literacy competencies can only be reflected in students assignments, projects and presentations [7].

\section{Information Seeking Behaviour}

The nature of Information Science as an interdisciplinary area is clearly reflected on the commonly used theories and methodologies in this field; the American Society of Information Science described Information science to be "concerned with the generation, collection, organization, interpretation, storage, retrieval, dissemination, transformation and use of information, with particular emphasis on the applications of modern technologies in these areas [8]. Information science has been affected by many disciplines such as education, psychology, computer science, sociology and philosophy and this interdisciplinary nature had resulted in many approaches and theories within this field. [9]

Through this definition of information science, information seeking behaviour is the area where we can study how people need, seek, give, and use information in different contexts, including the workplace and everyday living. There is no single definition for information seeking behaviour as it depends on the discipline where it is studied.

\subsection{Identification of Information Needs}

Identification of information need is a part of studying information behaviour was traditionally carried on individuals who describe their information needs in a form of query, using an information retrieval system. The focus on the individual is arguably coming from the traditional models and hypotheses in information behaviour that relies on the cognitive theory as Taylor [10] who had originally decomposed the information need into a sequence of four cognitive states, further investigation of the cognitive states lead to the hypothesis of anomalous state of knowledge (ASK) [11], this hypothesis proposes that the individual develops an information need when she/he does not posses sufficient knowledge to complete a task at hand. This gap between what the user knows and what is needed to complete a task is described as an anomalous state of knowledge (ASK), this hypothesis originates from an approach of individual cognitive of knowledge structure, Dervin [12] defined this gap as a deficiency that would prevent a person from making sense of the surrounding world. Those cognitive models have traditionally guided the research in information behaviour by investigating individuals’ activities.

\subsection{Kuhlthau's information seeking process (ISP) model}

Kuhlthau [13] has developed a model that describes six stages of information seeking process (ISP) that takes into account the information seeker's emotional, cognitive and physical experiences at different stages of the process. The model was motivated by an interest in investigating why users behave the way they do, even though the purpose of the investigation was to address a recognized gap between information systems and users' natural process of information seeking. According to Kuhlthau, the ISP is divided into six stages, which differentiate information searched for, ways of searching and relevance assessments, while moving the seeker from the initial state of recognized information need to the goal state of resolution. This movement is caused by a series of choices made through a complex interplay between three realms of activity: physical (the actions taken), cognitive (thoughts about the process and content) and affective (feelings experienced), the choices made by the information seeker are also influenced by environmental constraints, such as prior experience, knowledge and interest, information available, requirements of the problem and time allotted for resolution, these environmental criteria, though, have not been considered in the ISP model, the six stages of the ISP model are:

1. Initiation: recognize information need.

2. Selection: identify general topic.

3. Exploration: investigate information on general.

4. Formulation: formulate focus.

5. Collection: gather information pertaining to focus.

6. Presentation: complete.

Kathlau's ISP model has been used intensively in information behaviour research, and it is also based on the personal construct theory which describes a person's affective experience as he/she seeks 
information; Kathlau [14] described the anomalous states of knowledge as "cognitive uncertainty" that is followed by an "affective uncertainty" in which the user starts to seek information to relieve the affective uncertainty. In general this model has been used to study individual's information seeking behaviour, but this model has the potential to be applied in studying information seeking behaviour in team based courses which include design engineering courses.

\subsection{Collaborative Information Seeking Behaviour}

Collaborative information seeking and retrieval can be defined differently depending on the academic discipline that would emphasize on information searching, sharing, interaction and filtering during a collaborative work task. Foster [15] defined collaborative information seeking as "the study of the systems and practices that enable individuals to collaborate during the seeking, searching and retrieval of information."

\section{Information Seeking Behaviour of Engineers and Engineering Students}

Information behaviour in engineering has been the scope of many studies; some studies investigated information behaviour of engineers such as Ellis and Haugan [16] who categorized engineers' information seeking practice into eight categories which are:

1. Surveying: the initial search for an overview of the related literature within a subject field.

2. Chaining: following chains of different forms of connection between resources to identify new sources of information.

3. Monitoring: maintaining awareness of development and technologies.

4. Browsing: scanning of primary and secondary resources

5. Distinguishing: ranking information sources according to their relative importance

6. Filtering: using search strategies to make the retrieved information more relevant and precise.

7. Extracting: working through sources to select materials for specific use such as a presentation, a discussion, or a report.

8. Ending: activities involved with finishing the information seeking process at the end of the design project.

Veshosky [17] surveyed engineering teams working in engineering and construction firms regarding the resources of information they use for their design engineering projects, the results of the survey are shown in figure1, which shows that conversation with colleagues has a high priority, the library and librarians are in the middle of the curve.

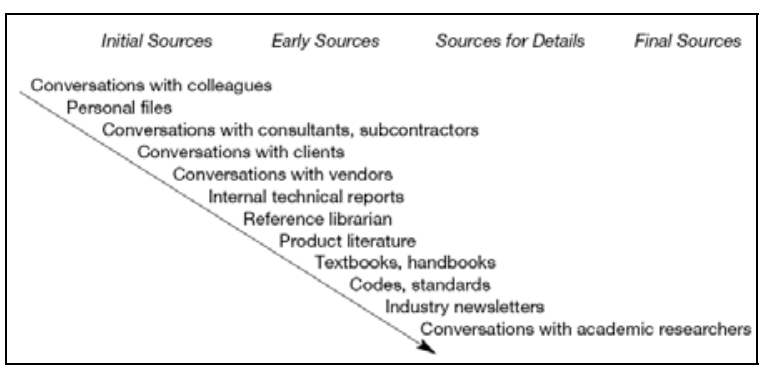

Figure1. Information-seeking behaviour during the problem-solving process [17]

The use of librarians and the services provided by librarians has been investigated in many studies including Tenopir and King [18] who argued that "Libraries sometimes aren't used by engineers because they are unaware of important services that are provided or because they don't fully appreciate the benefits of their use".

The collaborative nature of information seeking in design teams becomes a focus of some studies including Poltrock, Grudin, Dumais, Fidel, Bruce, \& Pejtersen [19] who investigated "collaborative information seeking” and "collaborative information sharing" in two design teams using collaborative tools; even though this research focused on information retrieval and sharing, it gave guidelines on how collaborative information behaviour can be studied on working groups rather than studying individuals and in this study the researchers identified five collaborative information retrieval strategies to include: identifying needs collaboratively, formulating queries collaboratively, retrieving information collaboratively, communicating about information and coordinating information retrieval activities. .Meanwhile, a multidimensional approach was suggested to study the collaborative information interaction by Fidel, Mark Pejtersen, Cleal, and Bruce [20] to include the cognitive dimension of individuals along with the specific task and decision, the organization of the teamwork, and the organizational culture, the same study recommended more multidimensional studies to enhance understanding of collaborative information behaviour, with this approach the study suggested to consider the social and organizational environment when studying collaborative information practice and that collaborative work should include a system that 
supports interactions between actors to "enhance their access to one another's knowledge, ideas, and opinions or help them keep on track”

\section{A Proposed Model to Investigate Collaborative Information Seeking Behaviour of Engineering Students}

This paper proposes a model that can be used to investigate collaborative information practice in a design engineering course, especially on design engineering student, The proposed approach relies on a model that has been developed by Eris and Leifer [21] for the design knowledge framework as shown in figure 2.

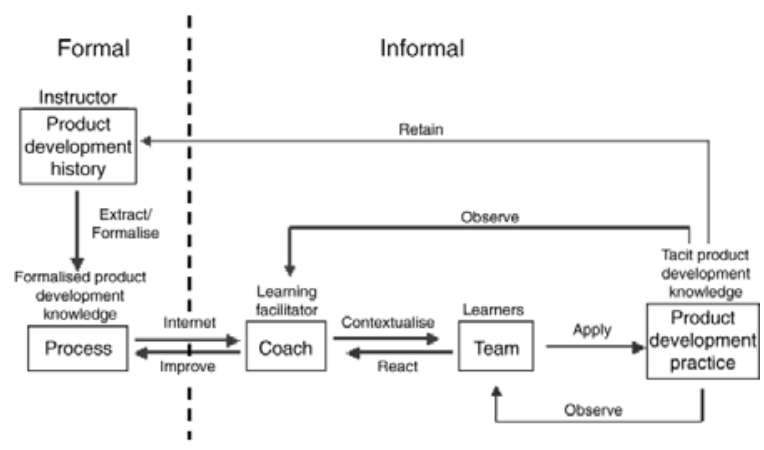

Figure 2. Design knowledge framework [21]

As the model proposed that there are two main areas within the design framework; the formal area where the instructor and students interact towards the final product/ design and the informal area where the team members interact, the model proposed a role for a "learning facilitator" within this process, the coach's role has been always assigned to a teaching assistant or a project manager, the developed model will include a librarian as a learning facilitator; the proposed model is shown in figure 3.

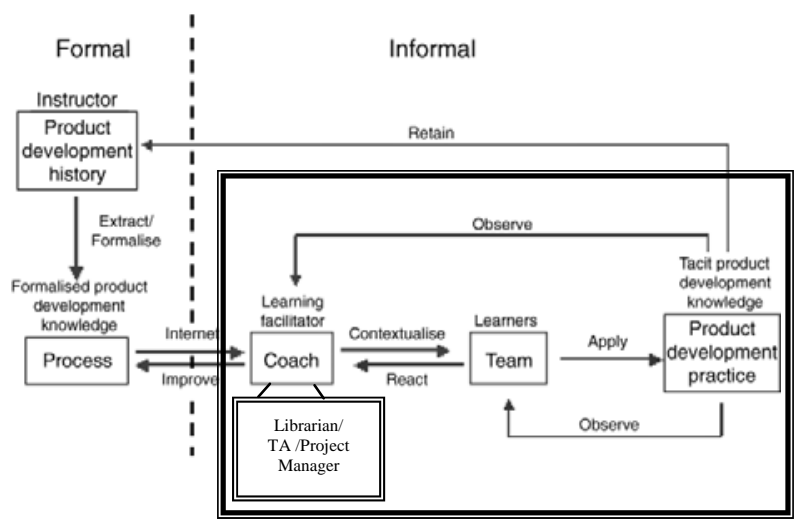

Figure 3. Design knowledge framework highlighting the librarian intervention
One of the advantages for the librarian in this model to study collaborative information practice of design engineering students that there is no formal involvement with students in those courses, where students learn how to discover the needed information for the project and manage them during the lifetime of the design project.

\section{Conclusion and Further Study}

The purpose of this paper is to introduce the need to study collaborative information practice in design engineering project with a highlight of the role of librarians and information specialists in studying and mapping the information resources that engineering students would use during the project lifetime. Also the study of collaborative information practice would lead to learn more about students' skills in managing and communication information. A preliminary research will take place in selected undergraduate design engineering courses at Queen's University to investigate students' collaborative information practice.

\section{References}

[1] National Science Board, Undergraduate science, mathematics, and engineering education, National Science Foundation, Washington, DC, 1986.

[2] National Science Board, NSB 00-1, Science and engineering indicators 2000, National Science Foundation, Arlington, VA, 2000.

[3] National Science Foundation, NSF 97-29 Undergraduate education: science, mathematics, engineering, and technology: Program announcement and guidelines, National Science Foundation, Directorate for Education and Human Resources, Division of Undergraduate Education, Washington, DC, 1997.

[4] The National Academy of Engineering, The engineer of 2020: visions of engineering in the new century, National Academy of Engineering Press, Washington, DC, 2004.

[5] CEAB Accreditation Criteria and Procedures. “Canadian Engineering Accreditation Board” [online]. Retrieved June 9, 2008, from http://www.engineerscanada.ca/e/files/report_ceab.pdf

[6] ABET Accreditation Board for Engineering and Technology. "Criteria for Accrediting Engineering Technology Programs” [Online]. Retrieved May 30, 2008 from http://www.abet.org

[7] ACRL Association of College and Research Libraries. "Information Literacy Standards for Science and Engineering Technology”. [Online] Retrieved June 18, 2008, from http://www.ala.org/ala/acrl/ 
[8] B.C. Griffith, Key papers in information science, Knowledge Industry Publications, New York, 1980.

[9] T. Saracevic, "Information science", Journal of the American Society for Information Science, Vol. 50, No. 12, 1999, pp. 1051-1063.

[10] R. S. Taylor, "Question-negotiation an informationseeking in libraries", College and Research Libraries, Vol. 29, No. 2, 1968, pp.178-194.

[11] N. J. Belkin and B. H. Kwasnik, "Using structural representation of anomalous states of knowledge for choosing document retrieval strategies”, Proceedings of the 9th Annual International ACM SIGIR Conference on Research and Development in Information Retrieval, 1986.

[12] B. Dervin, "From the mind's eye of the user: The sense-making qualitative-quantitative methodology", Qualitative Research in Information Management, 1992, pp. 61-84.

[13] C.C. Kuhlthau, "Inside the search process: seeking meaning from the user's perspective", Journal of the American Society for Information Science, Vol. 42, No. 5, 1991, pp. 361-371.

[14] C.C. Kuhlthau, Seeking meaning: A process approach to library and information services. Ablex Publishing, Norwood, NJ, 1993

[15] J. Foster, "Collaborative information seeking and retrieval", Annual Review of Information Science and Technology, Medford, NJ, 2006, Vol. 40, pp. 329-356.
[16] D. Ellis and M. Haugan, "Modelling the information seeking patterns of engineers and research scientists in an industrial environment", Journal of Documentation, Vol. 53, 1997, pp. 384-403.

[17] D. Veshosky, "Managing Innovation Information in Engineering and Construction Firms," Journal of Management in Engineering, Vol. 14, 1998, pp. 58-66.

[18] C. Tenopir and D. W. King, Communication Patterns of Engineers, Wiley-IEEE Press, Piscataway NJ, 2004.

[19] S. Poltrock, J. Grudin, S. Dumais, R. Fidel, H. Bruce and A. M. Pejtersen, "Information seeking and sharing in design teams," Proceedings of the 2003 International ACM SIGGROUP Conference on Supporting Group Work, 2003, pp. 239-247.

[20] R. Fidel, A. Mark Pejtersen, B. Cleal and H. Bruce, "A multidimensional approach to the study of humaninformation interaction: A case study of collaborative information retrieval," Journal of American Society of Information Science and Technology, Vol. 55, 2004, pp. 939-953.

[21] O. Eris and L. Leifer, "Facilitating product development knowledge acquisition: Interaction between the expert and the team”, International Journal of Engineering Education, Vol. 19, No. 1, 2003, pp. 142-152. 